\title{
Waterflooding for lateral anisotropy of porous media.
}

\author{
Shevelev Alexander Pavlovich \\ Tyumen State University \\ Institute of Physics and Technology \\ Tyumen, Russia \\ alexandershevelev@mail.ru \\ Valeev Asamat Salavatovich \\ OOO LUKOL West Siberia \\ OOO Lukol West Siberia \\ Kogalym, Russia \\ avaleev@mail.ru
}

\author{
Kotenev Yuri Alekseevich \\ GANU "Institute for Strategic Studies of the Republic of \\ Bashkortostan" \\ GANU ISIRB \\ Ufa, Russia \\ YAkotenev@mail.ru
}

\author{
Samsonov Kirill Yurievich \\ Tyumen State University \\ Institute of Mathematics and Computer Sciences \\ Tyumen, Russia \\ k.y.samsonov@gmail.com
}

\begin{abstract}
There are different types of the inside-the-pool flooding: dividing the deposit by injectors into lines, circles, creating a central row of dividing injection wells with several rows, going across, and those that are combined with marginal flooding. The injector pattern depends on the field's geological conditions and the terms of recovery. In the course of field development, the number of wells may increase, transferring row and block-row systems into dispersed ones. In case of laterally heterogeneous deposits, it is crucial to decide on the injectorproducer arrangement. The decision depends on the stress-strain analysis results, which reveal the formation's heterogeneity. The authors suggest drawing lines, which represent the direction of minimal stress, based on the well test data analysis. The idea is to locate the rows of injectors along these lines or to position disperse systems accordingly.
\end{abstract}

Keywords - waterflooding, lateral anisotropy, porous media.

\section{INTRODUCTION}

The most common way to maintain reservoir pressure while producing oil is water flooding. As a result, a lot of oilfields at the final stage of development are described as having a significant water cut and low water sweep efficiency due to lateral heterogeneity in permeability [1]. This makes it important to study how to adapt regular development systems to the formations described by distinctive lateral heterogeneity in their reservoir properties.

Lateral anisotropy in permeability causes significant changes in hydrodynamic processes going on in the formation. Horizontal heterogeneity causes deformation of displacement fronts, difference in water break-through to the producers and reduction in sweep efficiency.
Anisotropy of reservoir properties is defined by a number of reasons, including facies conditions, sedimentary environment, rock leaching, causing leached porosity, tectonic faults and stresses. An important factor causing lateral anisotropy is rock stress. The recent studies in formation stress-strain reveal that there are directions of minimum and maximum horizontal stresses. Along the maximum stress, the formation compresses and its porosity reduces. Along the minimum stresses, induced faults appear.

These factors combined cause formation structures to appear, which affect the reservoir properties of the formation and consequently the potential oil recovery.

\section{STUDIES IN FORMATION STRESS AND LATERAL ANISOTROPY}

Lateral anisotropy in permeability is described by three parameters: the direction of maximal permeability, its value and scope, which describes the formation heterogeneity at a certain level (starting with the grain orientation at the micro level to the presence of impermeable barriers or flow channels at the macro level) [2]. Different kinds of studies demonstrate different scopes of anisotropy. For instance, studying thin sections is a micro level, studying core is a mesolevel, depositional model LIL and well test analysis are macro level studies. It is obvious that the key to understanding the nature of anisotropy is combining the results acquired at every stage [3].

To study anisotropy of reservoir properties based on tracking analysis or well interference data, a spider plot for flow velocity is made, which represents the flow direction in the formation (Fig.1). 


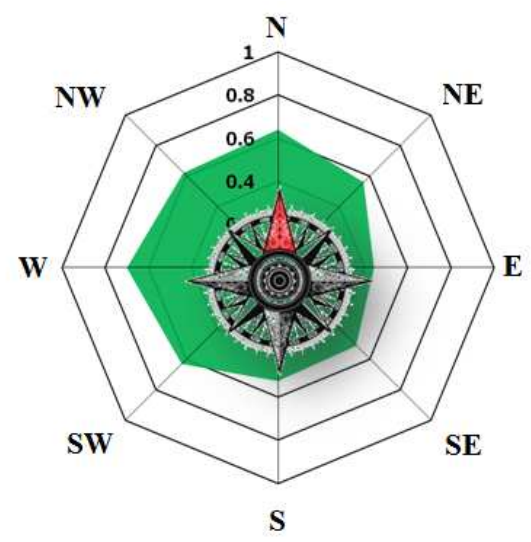

Fig.1. An example of a spider plot for flow velocity based on track analysis data.

However, such studies are rarely done because they are cost- and time consuming [4]. The main disadvantage of the described methods is the fact that they can only be applied at the late stage of field development associated with a high water cut.

Lateral anisotropy is commonly defined with the help of a well interference test. It is also possible to identify and consider lateral anisotropy based on studying space-oriented core samples, microstructure analysis of space-oriented thin sections and field data analysis. The kind of analysis depends on the availability of required conditions, i.e. on the degree of knowledge of a certain oilfield [5].

Since lateral permeability anisotropy plays an important role in distributing flows in the formation, it is important to assess it at the very first stage of field development to be able to design the most efficient flooding system. Wide use of hydraulic fracturing enables one to study the stress-strain in the formation during primary development. An example of such study is caliper logging [6]. The deviation in the wellbore geometry allows one to assess the stress directions and consequently the permeability anisotropy, as well as the state of the casing. This study provides the data to be used for early forecasting lateral anisotropy in the formations [7].

\section{FLOODING SYSTEMS DESIGN}

While designing flooding systems it is the vertical heterogeneity of the reservoir properties that is taken into account first. As we mentioned earlier, lateral heterogeneity is associated with the stress within the rock and it should be studied together with the vertical heterogeneity [8].

Water is most often injected outside or inside the oil-pool outline to maintain the formation pressure. Injecting water enables one to sustain the pressure in the formation and thus the initial production rates. When one deals with inside-thepool injection, water is injected through the system of injecting wells following a certain pattern within the oil-pool outline [9]. This is the most intensive system, which enables one to reduce recovery time and increase the production rate.

There are different types of the inside-the-pool flooding: dividing the deposit by injectors into lines, circles, creating a central row of dividing injection wells with several rows going across and combined with marginal flooding [10]. The injector pattern depends on the field's geological conditions and the terms of recovery.

In the course of field development, the number of wells may increase, transferring row and block-row systems into dispersed ones [11].

In case of laterally heterogeneous deposits, it is crucial to decide on the injector-producer arrangement. The decision depends on the stress-strain analysis results, which reveal the formation's heterogeneity [12]. It is suggested to draw lines, which represent the direction of minimal stress based on the well test data analysis. The idea is to locate the rows of injectors along these lines or to position disperse systems accordingly.

\section{WATER FLOODING EFFICIENCY IN LATERALLY HETEROGENEOUS FORMATIONS}

To evaluate the effect of aligning injectors according to the minimal stress lines, reservoir simulation for a row and a fivespot system was performed using Eclipse 100 SW.

The parameters for the simulation are shown in the table.

TABLE I. CHARACTERISTICS OF THE HYDRODYNAMIC MODEL

\begin{tabular}{|c|c|}
\hline Parameter & Value \\
\hline Length of the formation & $500 \mathrm{~m}$ \\
\hline Width of the formation & $500 \mathrm{~m}$ \\
\hline Thickness of the formation & $50 \mathrm{~m}$ \\
\hline Rock porosity ratio & 0.3 \\
\hline Absolute rock permeability & $30 \mathrm{mD}$ \\
\hline Initial formation pressure & $275 \mathrm{bar}$ \\
\hline Oil viscosity & $1 \mathrm{sP}$ \\
\hline Water viscosity & $0,024 \mathrm{sP}$ \\
\hline Gas viscosity & 800 \\
\hline Density of oil at the surface & 1000 \\
\hline Density of water at the surface & \\
& \\
\hline Density of gas at the surface & 0.7 \\
\hline Pressure in the producer & $270 \mathrm{bar}$ \\
\hline 3 day \\
\hline
\end{tabular}

The reservoir model considered the direction of minimal stress and consequently the formation anisotropy using different permeability values along $\mathrm{X}$ and $\mathrm{Y}$ axes.

The results of oil displacement dynamic simulation for the row system with the permeability ratio $\mathrm{Kx} / \mathrm{Ky}=3$ are shown in fig.2. The figure illustrates water saturation distribution at the moment in time, corresponding to the injection of 0.3 pore volume for different directions of the permeability anisotropy. As can be seen from the figure, the displacement front is more uniform in the cases when the row of injectors coincides with the direction of maximum permeability (or minimum stress). 

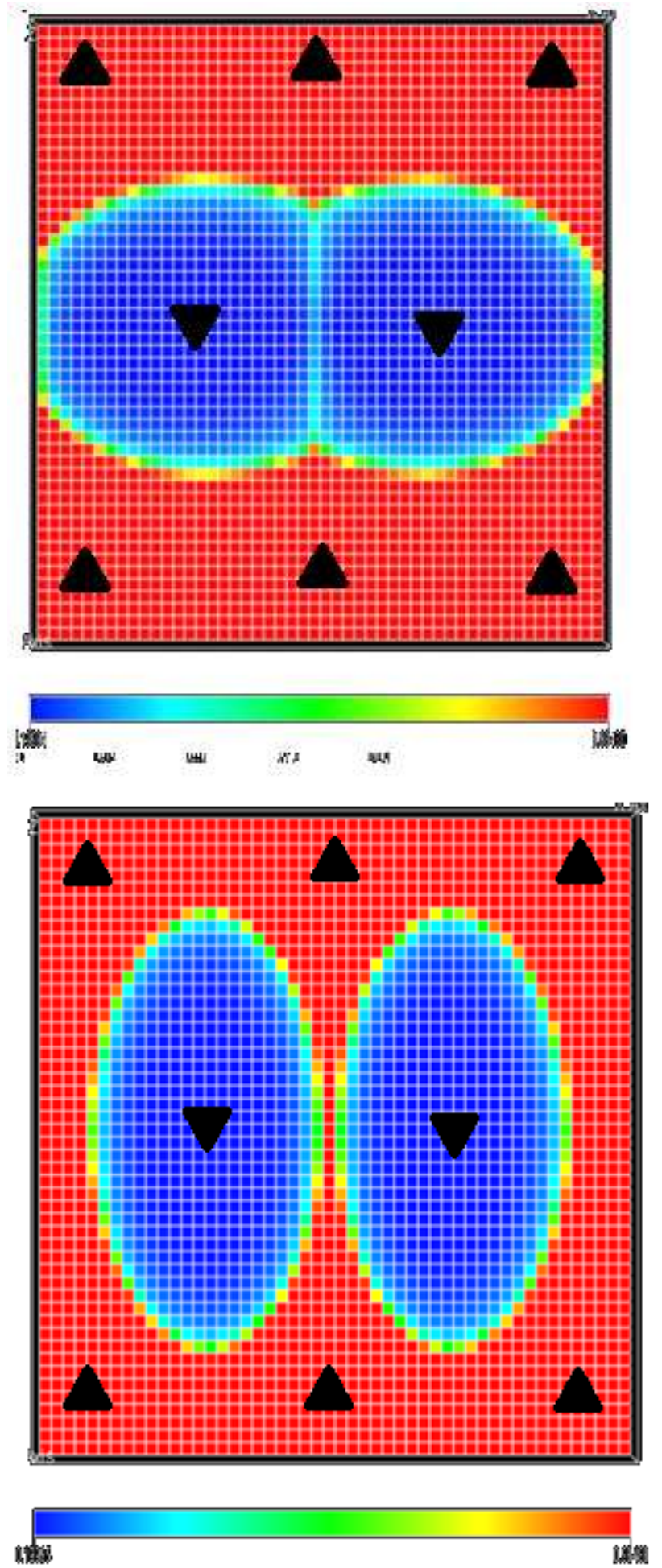

Fig.2. The results of oil displacement dynamic simulation for the row system with permeability ratio $\mathrm{Kx} / \mathrm{Ky}=3$ and $\mathrm{Kx} / \mathrm{Ky}=1 / 3$.

For higher anisotropy or bigger contrast in permeability $(\mathrm{Kx} / \mathrm{Ky}=10$ and $\mathrm{Kx} / \mathrm{Ky}=1 / 10)$, the results of simulation are shown in fig.3. The picture indicates that the displacement front heterogeneity is even more drastic.
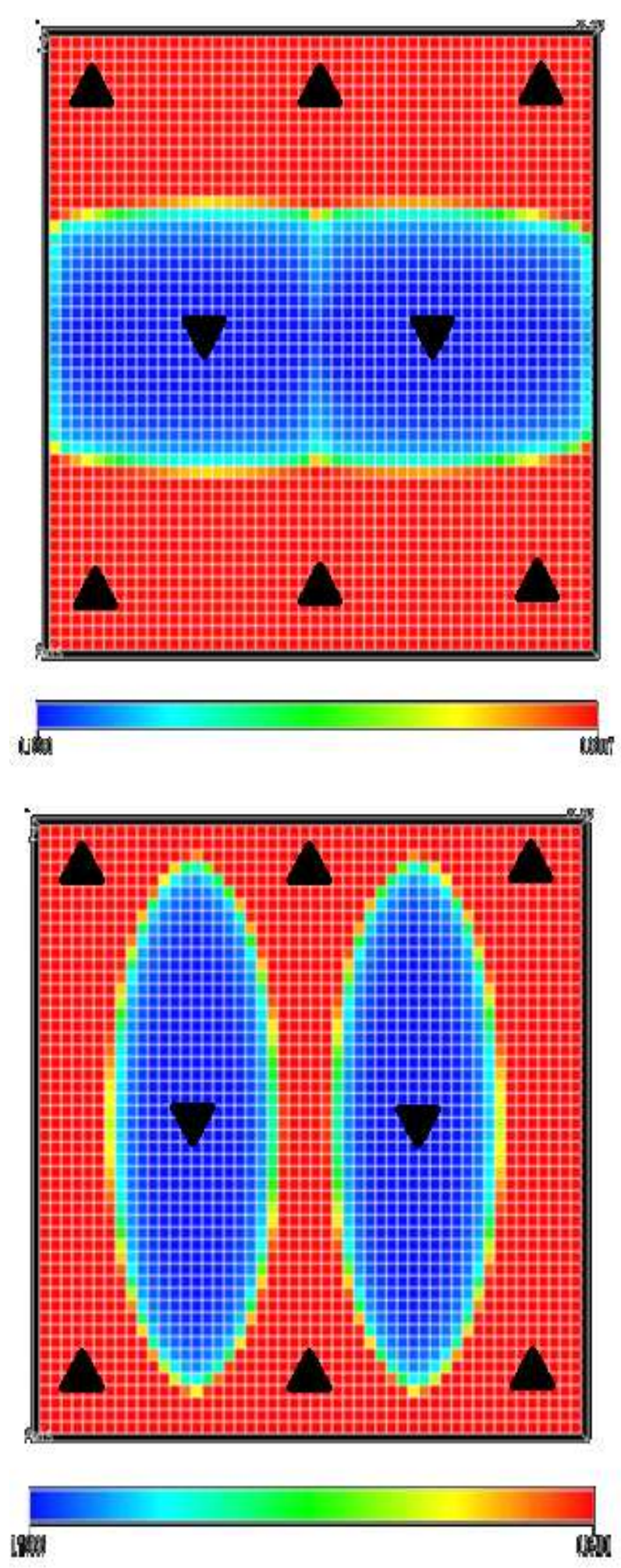

Fig.3. The results of oil displacement dynamic simulation for the row system with permeability ratio $\mathrm{Kx} / \mathrm{Ky}=10$ and $\mathrm{Kx} / \mathrm{Ky}=1 / 10$.

To do quantitative assessment of the water flooding efficiency with different well placement patterns, fig. 4 shows simulation of the dependence between the oil recovery factor and the water injection rate, expressed in pore volumes. As can be seen from the figure, water break-through to the 
producers happens almost 1.5 times later in case of proper placement of the injectors and producers. If one considers that the ultimate oil recovery is achieved after injecting three pore volumes then the right well placement can increase oil recovery by $3 \%$.
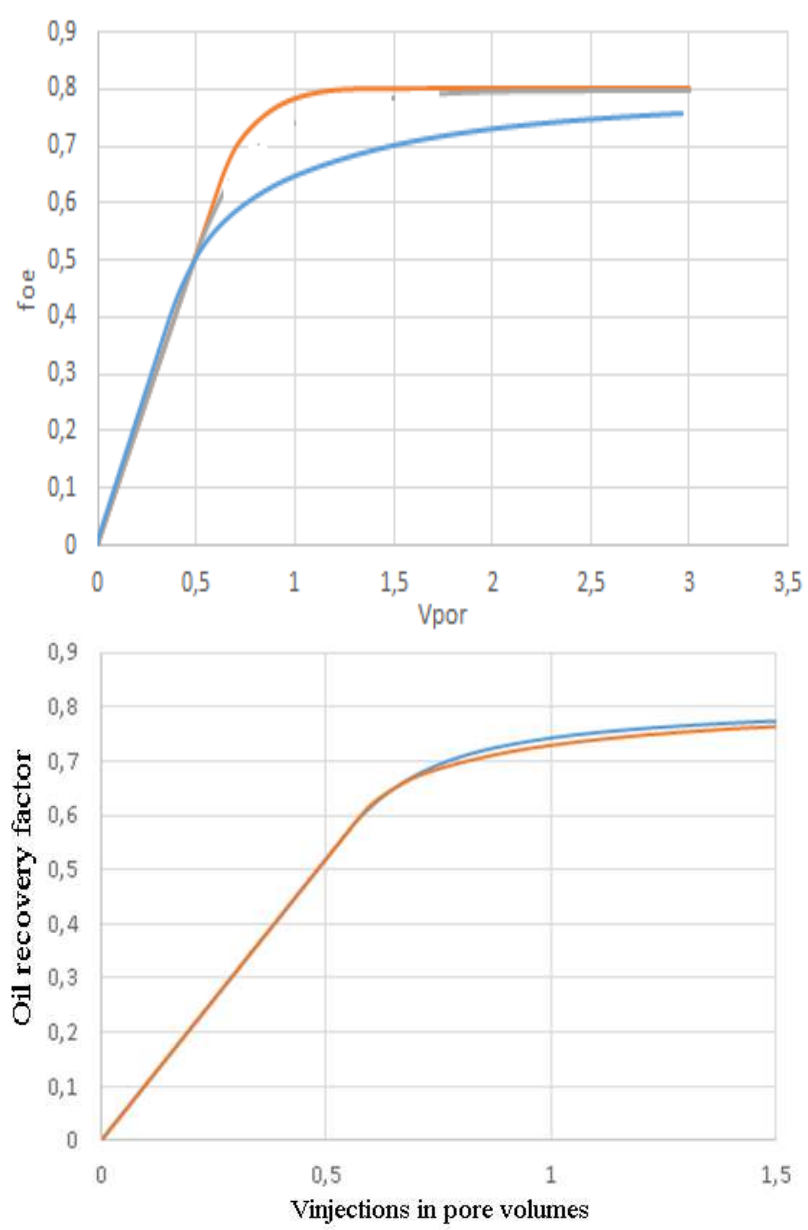

Fig.4. The dependence between the oil recovery factor and the water injection rate, expressed in pore volumes: $\mathrm{Kx} / \mathrm{Ky}=10$ and $\mathrm{Kx} / \mathrm{Ky}=1 / 10$ (left) and $\mathrm{Kx} / \mathrm{Ky}=3$ and $\mathrm{Kx} / \mathrm{Ky}=1 / 3$ (right), for the row flooding system, where Vinjection - injection volume, foe - fluid mobility, Vpor - porous volume.

For the five-spot system, the wells were located in the corners of the block and oriented along the formation anisotropy direction and with a 45-degree angle to the formation. The results of simulation with the permeability ratio $\mathrm{Kx} / \mathrm{Ky}=3$ are shown in fig.5. The figure illustrates water saturation distribution at the moment in time corresponding to the injection of 0.3 pore volume for different directions of the permeability anisotropy.
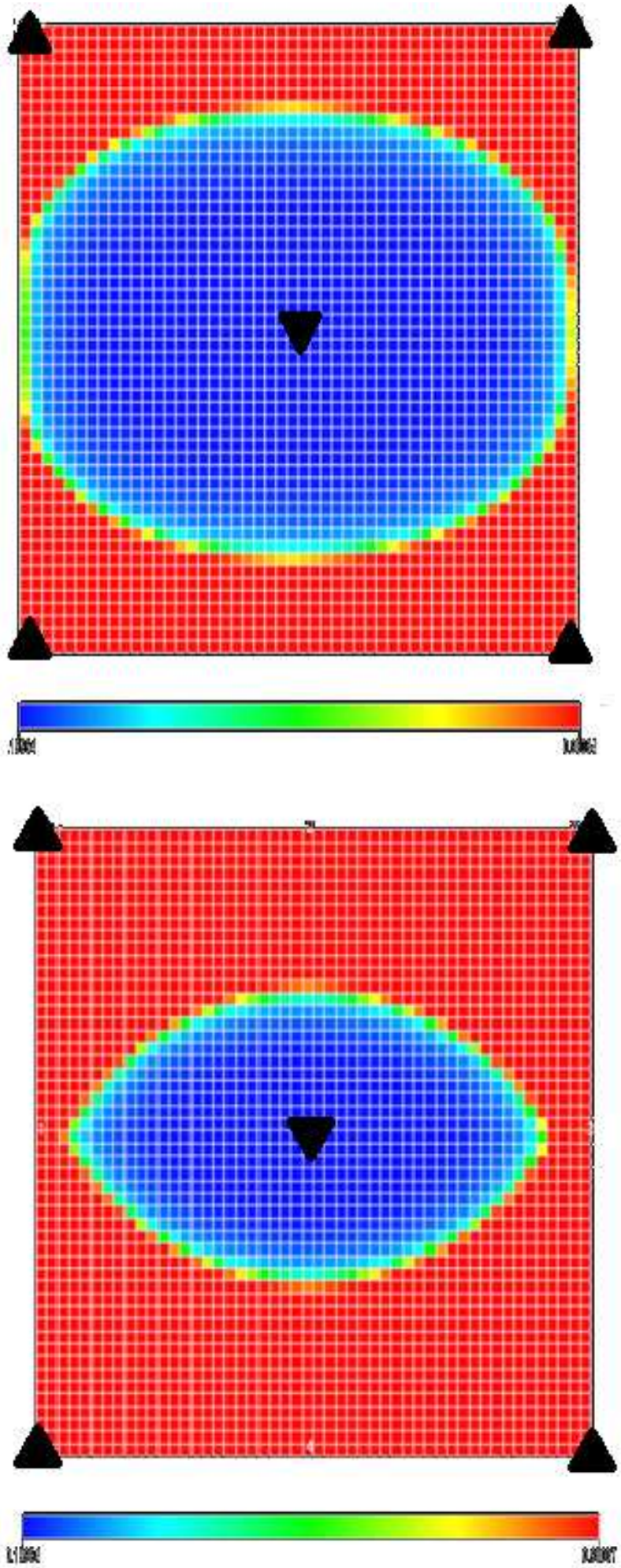

Fig.5. The results of simulation for the five-spot system with permeability ratio $\mathrm{Kx} / \mathrm{Ky}=3$ and $\mathrm{Kx} / \mathrm{Ky}=1 / 3$.

For higher anisotropy or bigger contrast in permeability $(\mathrm{Kx} / \mathrm{Ky}=10$ and $\mathrm{Kx} / \mathrm{Ky}=1 / 10)$, the results of simulation are 
shown in fig.6. The picture indicates that the displacement front heterogeneity is even more drastic.
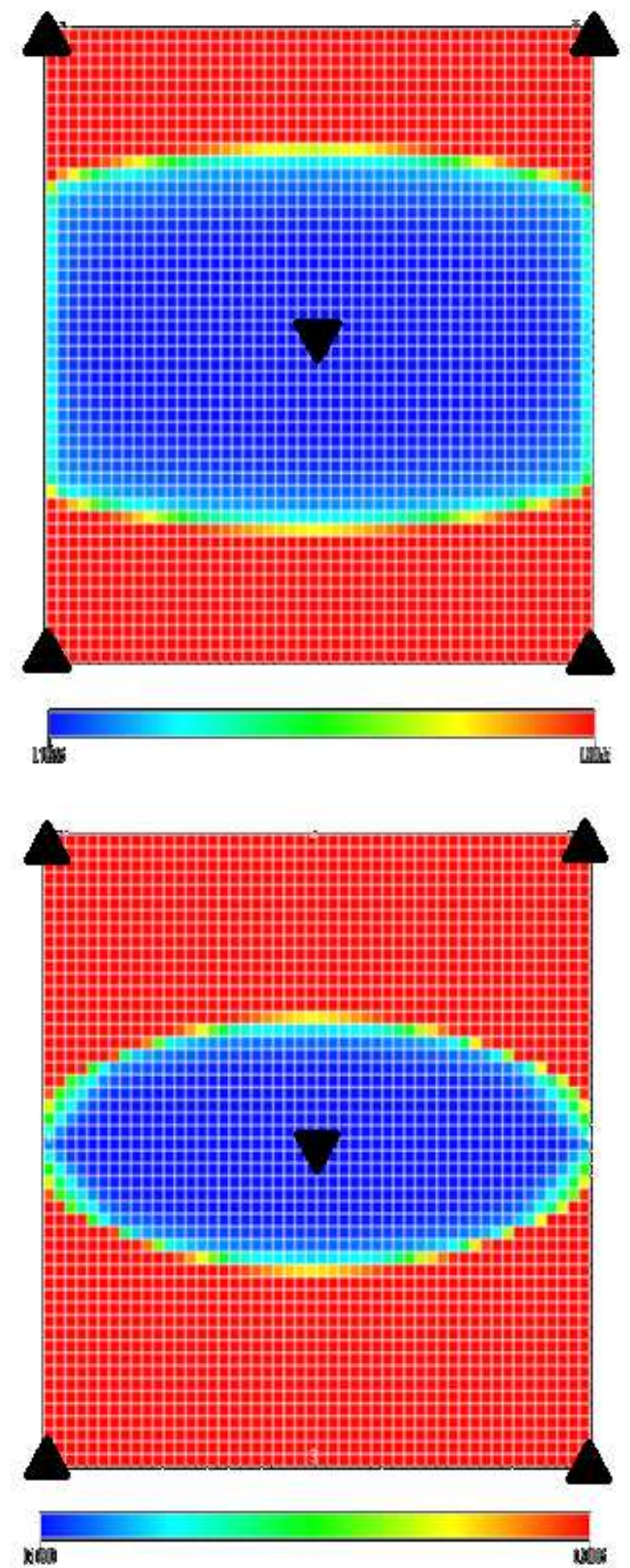

Fig.6. The results of simulation for the five-spot system with permeability ratio $\mathrm{Kx} / \mathrm{Ky}=10$ and $\mathrm{Kx} / \mathrm{Ky}=1 / 10$.
The quantitative assessment results for the water flooding efficiency with different well spacing patterns are shown in fig.7, which illustrates the dependence between oil recovery factor and water injection rate, expressed in pore volumes. As can be seen from the picture water break-through to the producers happens almost two times later in case of proper placement of the injectors and producers.
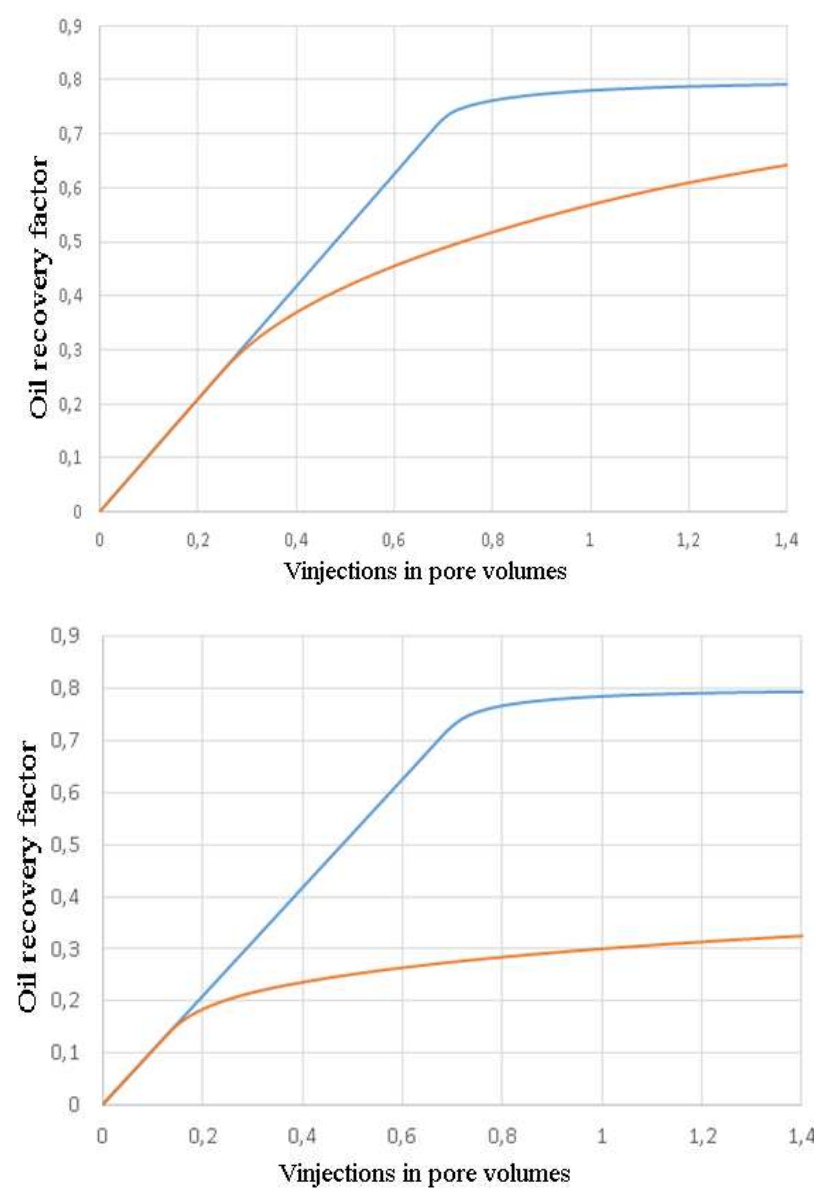

Fig.7. The dependence between the oil recovery factor and the water injection rate, expressed in pore volumes: $\mathrm{Kx} / \mathrm{Ky}=10$ and $\mathrm{Kx} / \mathrm{Ky}=1 / 10$ (left) and $\mathrm{Kx} / \mathrm{Ky}=3$ and $\mathrm{Kx} / \mathrm{Ky}=1 / 3$ (right), for the five-spot flooding system, where Vinjection - injection volume.

The analysis carried out in this work leads to a conclusion that taking into account lateral permeability anisotropy and the direction of minimal formation stress can increase the sweep efficiency and oil displacement due to proper well placement. Field production is enhanced due to a prolonging water-free production period and an increase of the ultimate oil recovery factor.

\section{CONCLUSION}

1) It has been demonstrated that modern studies of stress-strain at the early stage give an idea of the lateral anisotropy in the formation. 
2) It has been established that the formation anisotropy plays an important role for the sweep efficiency and injector-producer arrangement.

3) Proper correlation between the permeability anisotropy direction and injectors placement leads to prolonging the water-free production period and increasing the ultimate oil recovery factor.

4) It has been demonstrated that these results are achieved both for row and for dispersed injection systems.

\section{References}

[1] R.C. Earlougher,'Discussion of Interference Analysis for Anisotropic Formations", A Case History. Petrol. Tech. Trans. AIME, vol. 259, p. 1525, December 1975.

[2] H.Y. Chen, D.T. Hidayati, L.W. Teufel, "Estimation of Permeability Anisotropy and Stress Anisotropy From Interference Testing", SPE Annual Technical Conference and Exhibition. New Orleans. U.S.A., SPE Paper 49235, September 1998.

[3] H.Y. Chen, D.T. Hidayati, and L.W. Teufel, "A Quick Method to Diagnose Flow Anisotropy Using Interference Data", SPE Rocky Mountain Regional, Low Permeability Reservoirs Symposium. Denver, CO., SPE Paper 60290, March 2000.

[4] H.Y. Chen, D.T. Hidayati, L.W. Teufel, "Estimation of Permeability Anisotropy and Stress Anisotropy From Interference Testing", New
Orleans, LA., SPE Paper 49235 September 1998 [SPE Annual Technical Conference and Exhibition, 1998].

[5] A. S. Fadairo, O. A. Falode, S. B. Aderemi, "Oilfield Scale-Induced Permeability Damage Management During Waterflooding", San Antonio, SPE Paper 126116, September 2010 [SPE Annual Technical Conference and Exhibition].

[6] H.J. Ramey, "Interference Analysis for Anisotropic Formations", A Case History. Petrol. Tech. Trans., AIME, vol. 259, pp. 1290-1298. October 1975.

[7] J. R. Christensen, E. H. Stenly, A. Skauge, "Review of WAG Field Experience”. SPE REE, v.4, №2, 2001.

[8] K.M. Fedorov, A.G. Kolyagin, O.L. Krashkova, S.S. Gusev "Diagnostics and optimization of well operation as exemplified in G field operation in the Republic of Sudan”, Oil business, №6, pp. 106108, 2013.

[9] C. Hornandez, C. Alvarez, A. Saman, A. De-Jongh, N. Audemard "Monitoring WAG Pilot at VLEField, Maracaibo Lake by Rerfluorocarbon and Fluorine Benzoic Acids Tracers", SPE/DOE IOR Symposium, Tulsa, SPE paper 75259, 2002.

[10] L.I. Berge, J.A. Stonsen, B. Crapez, E.A. Qaule, "SAWG Infectivity Behavior Based on Siri Field Data", SPE/DOE IOR Symposium, Tulsa, SPE paper 75126, 2002.

[11] K.M. Fedorov, A.V. Kolmakov, V.A. Marishkin, A.S. Bordzilovsky, V.L. Terentiev, "Field development monitoring using integrated reservoir simulation" Oil business, №7, pp. 100-102, 2012.

[12] A.B. Rublev, A.U. Prokhorov, K.M. Fedorov, A.P. Shevelev, "Capillary-gravitational balance in cross-bedded heterogeneous formations”, TSU Newsetter, Oil business, № 6, 2010. 